\title{
Unexpected Exposure to Coronavirus Disease at the Endoscopic Room: What Should We Do?
}

\author{
Hyun Jeong Kim', Yong Hwan Kwon", , Seong Woo Jeon ${ }^{1,2}$, Su Yeon Nam', Hyun Suk Lee ${ }^{1,2}$, Joon Seop Lee', Chang Min Cho ${ }^{1,2}$, \\ Ki Tae Kwon ${ }^{2,3,4}$, Ji Yeon Ham ${ }^{2,5}$, Changho Kim ${ }^{2,6}$ \\ Division of Gastroenterology, Department of Internal Medicine, Kyungpook National University Hospital ${ }^{1}$, Department of Internal Medicine, \\ School of Medicine, Kyungpook National University ${ }^{2}$, Department of Infection Control and Management, Kyungpook National University \\ Chilgok Hospital ${ }^{3}$, Division of Infectious Diseases, Department of Internal Medicine, Kyungpook National University Chilgok Hospital ${ }^{4}$, \\ Department of Laboratory Medicine, Kyungpook National University Hospital ${ }^{5}$, Department of Emergency Medicine, School of Medicine, \\ Kyungpook National University ${ }^{6}$, Daegu, Korea
}

As of August 5, 2020, the number of confirmed coronavirus disease-2019 (COVID-19) cases have reached a total of 14,456 in the Republic of Korea, and 6,943 (48\%) of these were from Daegu. ${ }^{1}$ The number of endoscopy cases in our center has decreased by approximately 20\% compared to the same period in 2019. Current guidelines suggest deferring elective endoscopies during the 2019-novel coronavirus (nCoV) outbreak. ${ }^{2}$ However, as the daily number of newly diagnosed COVID-19 cases tends to decrease over time, scheduled endoscopy for patients with serious illnesses such as gastrointestinal malignancies cannot be delayed anymore. Therefore, indefinite deferring of scheduled endoscopies may not be the ultimate solution, especially this COVID-19 outbreak is expected to continue for a prolonged period. However, as fecal-to-oral transmission can be a route for transmission of the virus, performing endoscopies can pose great danger to both patients and the medical unit. ${ }^{3}$ Therefore, emphasis on precaution and scrutiny for the prevention of the infection must be practiced.

On April 1, 2020, a 48-year-old man visited our center for upper gastrointestinal endoscopy as 1-year follow-up study after distal gastrectomy for advanced gastric cancer on March 2019. He did not show any symptoms which were suspicious of COVID-19 when he visited the endoscopy room. He underwent sedative upper gastrointestinal endoscopy. One

Received: July 29, 2020 Revised: August 3, 2020 Accepted: August 5, 2020

Corresponding author: Yong Hwan Kwon

Division of Gastroenterology, Department of Internal Medicine, Kyungpook National University Chilgok Hospital, 807 Hoguk-ro, Buk-gu, Daegu 41404, Korea Tel: +82-53-200-2609, Fax: +82-53-200-3089, E-mail: tear1480@hanmail.net endoscopist and one assistant nurse participated in the procedure, during which personal protective equipment (PPE) were worn as recommended from the Department of Infection Control and Management at our hospital (KF-94 mask, single-use surgical gown, and surgical gloves). The same assistant nurse checked the vital signs of the patient from the waiting room to the recovery area. The patient wore a mask before and after endoscopy, except during the procedure. On April 10, 2020, the patient visited the outpatient clinic of the Department of General Surgery, and computed tomography of the chest (which was scheduled as postoperative 1-year follow-up study) showed ill-defined ground-glass opacities in both lower lobes of the lungs. Suspicious of viral pneumonia, the professor of the Department of General Surgery, who examined the patient, recommended performing a test for COVID-19, and the patient was confirmed positive. The result was reported within 6 hours from the test, for which Department of Infection Control and Management was notified, and the patient was immediately admitted to a local medical center for COVID-19 quarantine. Simultaneously, the Department of Infection Control and Management also notified all the personnel of the endoscopy center; rapid polymerase chain reaction (PCR) tests were performed for 10 endoscopists, nine assistant nurses, two nurses at the recovery area, two receptionists, and five research investigators at 09:00 PM on the same day. The results were reported at 05:00 AM the next day; fortunately, no one showed a positive result for the virus. After this event, every staff in endoscopy room was checked and monitored for fever and relevant symptoms

Copyright $\odot 2020$ Korean College of Helicobacter and Upper Gastrointestinal Research

(a) The Korean Journal of Helicobacter and Upper Gastrointestinal Research is an Open-Access Journal. All articles are distributed under the terms of the Creative Commons Attribution Non-Commercial License (http:// creativecommons.org/licenses/by-nc/4.0) which permits unrestricted non-commercial use, distribution, and reproduction in any medium, provided the original work is properly cited. 


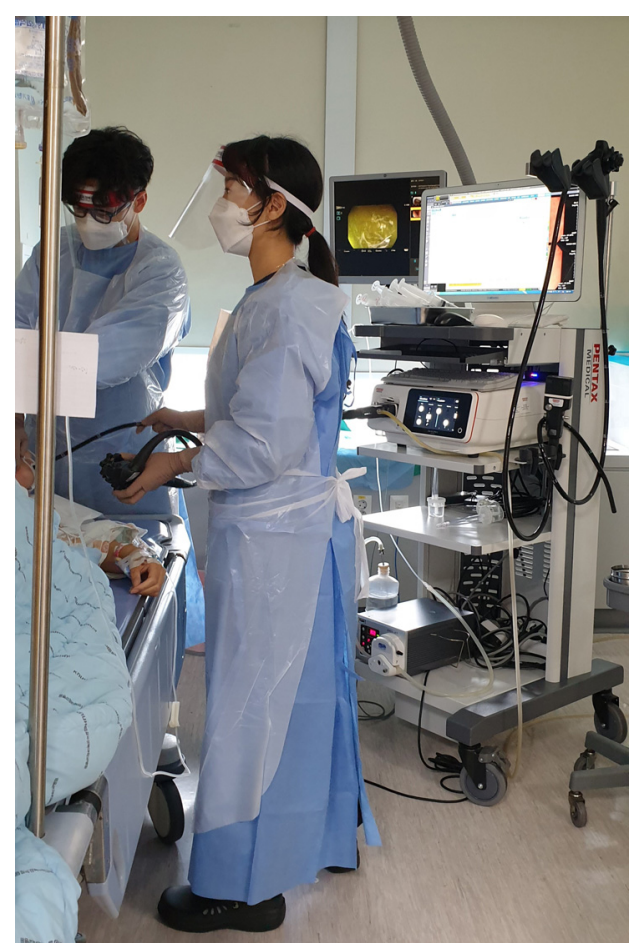

Fig. 1. Medical staff in the endoscopy center, wearing the personal protective equipment recommended by the Department of Infection Control and Management of our hospital, which includes a KF-94 mask, face shield, surgical gown, gloves, and disposable single-use vinyl gown.

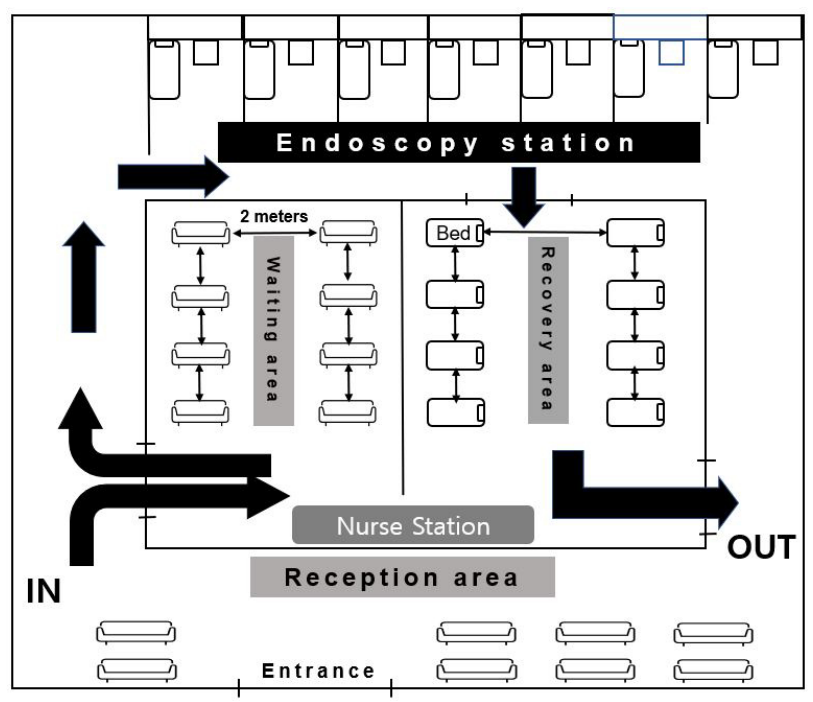

Fig. 2. Schematic diagram of the endoscopy center. Each endoscopy station is separated by a concrete wall. Contact between patients is minimized by the distance and structures such as curtains, walls, or partitions. The distance between patients in the recovery and waiting areas is at least $2 \mathrm{~m}$, which is denoted by the double-headed arrows. Each bed in the recovery area is surrounded by separate curtains. The recovery and waiting areas are separated by a partition. The bald arrows indicate the flow of patients during endoscopic examination. for the following 2 weeks. One endoscopist showed upper respiratory symptoms (rhinorrhea and cough) during this period and he was tested follow-up PCR tests, which confirmed negative, respectively. No other staff had relevant symptoms, and hospital infection was not reported. In addition, we also tracked the patients who were in the recovery area with the 2019-nCoV positive patient. A total of seven patients were discovered and five tested for the virus within a day after endoscopy personnel were notified; the results confirmed negative for the five patients. The remaining two patients were not tested for COVID-19, because they were lost in the follow-up.

We assume negative results for the virus of the whole medical staff is due to the strict policy and adherence to PPE, which was advised and recommended by the Department of Infection Control and Management. After this incidence, PPE recommendations were revised to add facial shield and disposable single-use vinyl gown (Fig. 1). Furthermore, every patient is now being separated from other patients at least $2 \mathrm{~m}$ in distance at the waiting and recovery areas (Fig. 2, 3).

In this unexpected situation, all endoscopic units were able to return to work without significant delay owing to prompt notification and examination, in cooperation with the Department of Infection Control and Management. To perform safe endoscopy in the time of pandemic, prevention of viral transmission either from the patient to the medical team or from the medical team to the patient is extremely important. To prevent unexpected exposure to COVID-19, personal history-taking before endoscopic examination and adherence to be equipped with PPE are recommended by the current guideline and literature. ${ }^{4-6}$

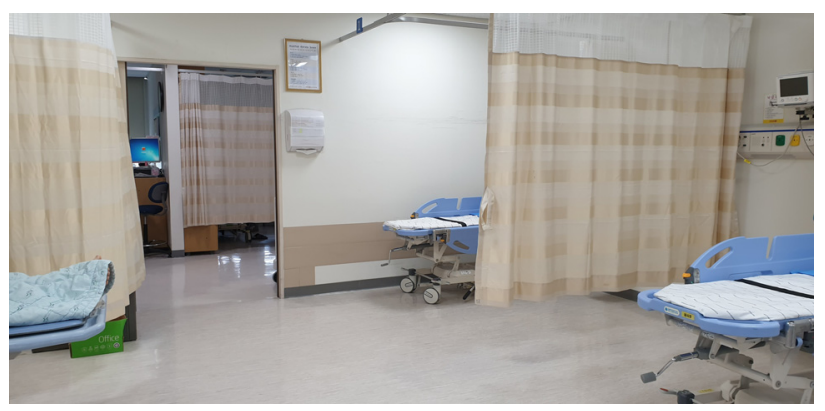

Fig. 3. The recovery room of the endoscopy center. The beds are at least $2 \mathrm{~m}$ apart. 
As in our case, wearing PPE might be a strong preventive strategy from exposure to COVID-19 during invasive medical procedures. However, asymptomatic patients with COVID-19 could easily be missed to be the source of a hospital outbreak. Thus, if a unit within a hospital is unexpectedly exposed to COVID-19, rapid testing of the relevant personnel would be another strategy for the normalization of work at the department. To conduct this strategy, prompt communication and cooperation among the Department of Infection Control and Management, laboratory center, and clinicians is needed. To safely perform elective endoscopies, hospitals with endoscopy centers should be prepared with such coherent system.

\section{CONFLICT OF INTEREST}

No potential conflict of interest relevant to this article was reported.

\section{ORCID}

Hyun Jeong Kim il https://orcid.org/0000-0003-2664-7577

Yong Hwan Kwon (1) https://orcid.org/0000-0002-0520-9685

Seong Woo Jeon (1) https://orcid.org/0000-0002-9539-9389

Su Yeon Nam (1) https://orcid.org/0000-0002-5568-7714

Hyun Suk Lee (1) https://orcid.org/0000-0001-9288-0321

Joon Seop Lee (1) https://orcid.org/0000-0003-4702-917X
Chang Min Cho (1) https://orcid.org/0000-0002-9903-1282

Ki Tae Kwon (1) https://orcid.org/0000-0003-4666-0672

Ji Yeon Ham (1) https://orcid.org/0000-0002-7638-0658

Changho Kim (1) https://orcid.org/0000-0002-7552-8200

\section{REFERENCES}

1. Korea Center for Disease Control. Number of confirmed cases of COVID-19 in Republic of Korea in 2020 [Internet]. Sejong: Ministry of Health and Welfare [cited 2020 Aug 5]. Available from: http://ncov.mohw.go.kr/bdBoardList_Real.do?brdId= $1 \&$ brdGubun $=13 \&$ ncvContSeq=\&contSeq=\&board_id=\&gubu $\mathrm{n}=$.

2. Song Y, Liu P, Shi XL, et al. SARS-CoV-2 induced diarrhoea as onset symptom in patient with COVID-19. Gut 2020;69:11431144.

3. Jung $\mathrm{SH}$, Oh JH. Gastrointestinal symptoms in patients with COVID-19 and usefulness of stool test. Korean J Helicobacter Up Gastrointest Res 2020;20:86-90.

4. Gu J, Han B, Wang J. COVID-19: gastrointestinal manifestations and potential fecal-oral transmission. Gastroenterology 2020; 158:1518-1519.

5. Repici A, Maselli R, Colombo M, et al. Coronavirus (COVID-19) outbreak: what the department of endoscopy should know. Gastrointest Endosc 2020;92:192-197.

6. Advani SD, Smith BA, Lewis SS, Anderson DJ, Sexton DJ. Universal masking in hospitals in the COVID-19 era: is it time to consider shielding? Infect Control Hosp Epidemiol 2020. doi: 10.1017/ice.2020.179. [Epub ahead of print] 